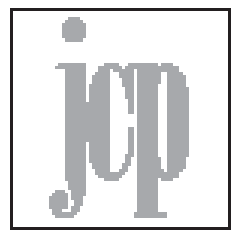

\title{
Contemporary Tamil Dalit Feminist Poetics
}

\author{
Pramila Venkateswaran
}

Nassau Community College, New York

Pramila.venkateswaran@ncc.edu

\section{ABSTRACT}

Contemporary Tamil Dalit feminist poets challenge dominant ideas in mainstream Hinduism with its inscribed caste and gender discriminations oppressing Dalits. Writing in the spoken Tamil familiar to all Tamil speaking people, they address the struggles of Dalit women in daily life, their sexual oppression, and their desire for autonomy. I examine the social and political themes and aesthetics of Tamil Dalit feminist poetry in the light of the rationalist and materialist theories of Dr. Ambedkar and E.V. Ramasamy Naicker (known as Periyar). Poets such as, Meena Kandasamy, Sukirtharani, Malathy Maithri, Ku Uma Devi, and N.D. Rajkumar write on themes of sexuality, caste oppression, and gender oppression, thus openly defying assumptions about Dalit women and challenging caste dominant rules of poetry, society and language. These poets' concerns can be traced to the lineage of Dalit song traditions which were ceremonial and political, as well as the anti-caste movement in Tamil Nadu led by Periyar. Today's Dalit feminist poets in Tamil Nadu continue to be energised by Periyar's challenge to nationalist politics, decolonising hegemonic gender and caste ideologies. They use imagination and logic to articulate their challenge to caste hegemony and present the interconnection of land, body and sexuality, thus claiming their subjectivity.

Keywords:Dalit feminist poetics, caste and gender oppression, rationalist and materialist theories of Ambedkar and Periyar, decolonisation, claiming subjectivity 
Prominent Tamil Dalit feminist poets Sukirtharani, Malathi Maitri, Meena Kandasamy, Ku Uma Devi, Rajkumar, and many others have risen to critical acclaim in India through the attention given to them by major critics, such as Lakshmi Holmstrom. Dalit poetry springs out of caste apartheid, out of the hegemonic relationship between upper castes and lower castes (Shudras and Dalits) based on the sacerdotal sanction of power. Dalit women also bear the price of humiliation of being used and abused, raped, bound in some states in the last century to local precepts of baring their breasts in front of upper caste men, religiously-mandated prostitution and other gendered degradations. One of the latest incidents has been the 'honor' killing of Dalit men and women who elope or marry upper caste lovers. Dalit feminism rises out of collective rage against their humiliation and the refusal to be broken down. By weaving together caste and gender oppressions, Dalit poetry lays bare the oppressive caste hierarchy in Indian society. Their poetics radically challenges binary thinking, such as man/woman, upper/lower, body/spirit. Dalit Tamil poetry is radical. Radical means root. So at its root, Dalit Tamil poets deconstruct Hindu religious belief based on the caste system and its attendant customs, thus annihilating the insidiousness of caste structures prevalent today. By placing emphasis on the Dalit female body as the site of pain inflicted by the hegemons, Dalit feminist poets "combine aesthetics with the political" (Kumar 71) to reclaim their voices and their bodies. In doing so, they attempt to "raise the reader's consciousness of fundamental values like equality, freedom, justice and fraternity" (Limbale qtd. in Kumar 71). Thus the poetic text, just like other literary forms in Dalit literature, makes "ethical claims about the world" (Gajarawala 18). These poets mentioned above show the power of their poetry, its magical quality of bringing to light lives considered marginal. In their writing, they involve their audience, whether they are allies or are at odds with Dalit truth telling. They rely on an "unwritten compact between reader and writer" (Gajarawala 18); thus, the audience is involved in political inquiry and is questioned, laughed at and with, and is invited to join in protest.

Dalit feminist poetry in each of the regions and languages of India, has its own unique history. In this paper I look at contemporary Tamil Dalit feminist poetry, in Tamil Nadu. Tamil Dalit feminist poets subvert language superiority; they challenge the diglossia ${ }^{1}$ of Tamil and choose to write in the spoken Tamil familiar to all Tamil-speaking peoples within and outside Tamil Nadu and outside India. Their themes are nature (environment) as continuous with human nature, 
sexuality, spirituality, and challenge dominant ideas in mainstream Hindu culture. Dalit Tamil poets write their poems from struggle and of struggle, debunking assumptions about Tamil high culture as well as skepticism about the validity and authenticity of Dalit poetry. They defy religious rituals and customs and use lampoon and satire to unseat the center, which is Hindu, Brahmin, patriarchal, and nationalist. Dalit feminist poetry is being translated into English only recently. Since there is a paucity of translations of Tamil poetry, I am using my own translations wherever needed. ${ }^{2}$

Bhimrao Ramji Ambedkar and E. V. Ramasamy Naicker, two major thinkers of the $20^{\text {th }}$ century, addressed the very root of the designation 'untouchable' caste assigned to Dalits. While Ambedkar looked deeply into the historical root of caste prejudice, Naicker (or Periyar as he is commonly called) addressed the roots of patriarchy and caste oppression. Their inquiry and recommendation of caste annihilation and women's liberation set the wheels of decolonisation turning in not only Dalit ideology and their current political and literary expression but in India as a whole. Ambedkar's and Periyar's critical inquiries are at odds with current ideas of nation, woman, caste, and Hindu political hegemony that are in vogue. These luminaries advanced a radical systemic shift toward democracy, which is viewed as a threat by current Hindutva ideologues. In this paper, I use Periyar's seminal text, Why areWomen Enslaved? to show how rationalist and materialist ideas serve as anchors for the Dalit movement in Tamil Nadu. I use theorists engaged in writing about caste in South Asia, rather than European and American theorists, since "traditional literary theories, however radical they may be, will not be able to do justice to the kind of reading Dalit literature demands" (Kumar vi). I argue that we can see materialist and rationalist principles as the energies fueling Dalit Tamil feminist poetry. It is important to note that Periyar's rational and materialist ideology is in opposition to Hindu Vedic spiritual idealism, and so it needs to be understood within the Dravidian culture (the original inhabitants of South India) and the context of Tamil Nadu. It has to be distinguished from European Enlightenment rationalist thinking that propelled colonialism. Periyar believed in using reason to understand and solve human problems. In contrast, Vedic idealism, which was based on the philosophy of Advaita ${ }^{3}$ or non-dualism, believes in the world as maya, or illusion, and that one needs to believe in the Ultimate, the self being a part of the Ultimate. Since Hinduism, which is a latter day name for Vedic philosophy, lays emphasis on the unseen Supreme Being, and 
because the caste system (varnashrama) was woven into the fabric of attaining this ultimate knowledge, Periyar felt it failed to address the discriminations that women and men, who were lower caste, faced daily. Periyar believed in logic based in science and reason, while Vedic idealism prevented people from using reason to take action to change their condition (Sivaiah).

Periyar's rationalism, which "invested in the surface materiality of things" (Gajarawala 18), offered strategies for decolonisation. ${ }^{4}$ How to unglue oneself from the clutches of cultural colonisation of the mind and one's creativity? This is a perpetual question for 'post' -colonial peoples. In literature, the arts, and in feminist studies and activism, writers and scholars enact creative ways of getting out from under the burden of colonisation. Dalit feminist poets use strategies of interrogation, analysis, subjectivity, with their attendant rhetorical devices of irony, wit, and humor and to radically challenge the very basis of their condition. In claiming the name 'Dalit', which means 'broken', 5 rather than the degrading and paternalistic terms 'Depressed Classes' or 'Harijan', ${ }^{6}$ the subalterns ${ }^{7}$ spoke out in the $20^{\text {th }}$ century, thus spearheading a political movement with which people from across class, caste and racial boundaries can seek solidarity. In claiming this new nomenclature, Dalits began their process of decolonizing not only from insidious elements of the colonial era and nationalistic thought but from Brahmin and Hindu supremacy.

\section{Caste and Gender Oppressions as Themes in Dalit Feminist Poetry}

Dalit feminist poetry dismantles the State's ideas of nationalism, casteism, and all exclusionary structures that do not include caste as a category of analysis. During India's struggle for independence from British colonial rule, nationalist leaders and social reformers addressed women's struggles within the patriarchal family, linking the protection of the honor of woman with the honor of the nation (Chatterjee 251). The Women's India Association was formed in 1917, which later became the All India Women's Conference in 1926 (Guha 243); both were formed as a taskforce to engage with women's issues. The 'women's question', which only addressed middle and upper class women, and overlooked casteism, dropped in importance once Independence and the Partition took place (Chatterjee 251). However, in Tamil Nadu, Periyar, a feminist even before that term became prevalent in discourses about women's rights, pursued the topic of women's liberation in his self-respect movement, an anti-Brahmin movement, 
which he began in 1925. In parallel, he pushed for dismantling the caste system and establishing "a separate country for the Tamils" (Guha 224), as a way to break away from the hegemony of the North as well as the central government. His outspoken ideas regarding women's freedom, his espousal of atheism, and his critique of caste earned him a permanent place in Indian letters. Periyar's pronouncements went to the root of Indian ethos. He believed in women's freedom to choose her partner, marry more than once, and plan her family. He believed that domesticity for women hampered their advancement, so he advocated women's choice to be childless. He questioned the double standards regarding women's chastity when this rule did not apply to men. In his final chapter in WhyWere Women Enslaved?, he writes, "if women have to attain true liberation, it is essential to destroy the concept of godliness that is responsible for the god-created 'masculinity' and 'femininity'” (Periyar 64).

Tamil Dalit feminist poets share Ambedkar's and Periyar's rational and materialist ideology. The aesthetics of their writing reveal the rationalist core of looking at things as they are, no matter what religion they have converted to. For example, when Dalit feminist poet Sukirtharani describes feminism, she offers examples from real life experiences to reveal the lacunae in middle and upper class feminism of the $20^{\text {th }}$ century. She explains,

Feminism is supposed to be inclusive. And if there's space for Dalit writing, so why shouldn't there be one for Dalit women, I thought. We can never define feminism by one standard. My language of feminism is different from yours. For some, feminism may be about having the right to go to pubs and stay out late at night. For me, feminism is having the right to be able to step out of the house, and both are equally important. (Sukirtharani "Interview")

She echoes African American feminists who point out that while white feminists were pushing for libidinal freedoms and the right to work, black women were engaged in fighting for the right to vote, get access to education and work, and protect their people from police brutality. From Sukirtharani's statement about Dalit feminist vision, we see the gap that exists between middle class savarna feminism (upper caste) and Dalit feminism. Dalit feminists simultaneously challenge patriarchy, class, upper caste hegemony and middle and upper class feminists who engage in scholarship and activism that fail to include caste. By highlighting caste discrimination in their poetry, Dalit feminist poets radically change feminist discourse.

Dalit feminist poets perform their feminism in poetry, theatre and novel, thus challenging the forces of patriarchy and caste oppression in their local lan- 
guages. In Tamil Nadu where Periyar has been a strident voice over the course of the $20^{\text {th }}$ century, decrying untouchability and espousing atheism and feminism based on rationalism, Tamil Dalit feminist poets continue his political argument in critiquing caste or varna ${ }^{7}$ as well as patriarchy. Meena Kandasamy and Sukirtharani question concepts of 'purity' in language, the female body, and the casteised body. Just as the Lokayata, in the $6^{\text {th }}$ century BCE "propagated a materialistic philosophy as opposed to the idealism of the Upanishads and the Vedas" (Kumar 21), Dalit poets show the insidious and culturally and religiously-sanctioned concept of "untouchability" based on the pollution rules of the varna system of stratification from centuries ago. The concept of the pure Brahmin, or upper caste, arose in the four-tier varna or caste hierarchy during Vedic times. The people who carried the carcasses of cows were relegated to the outskirts of villages and considered impure, and therefore untouchable. "Ambedkar argued that the Vedic Brahmins had been meat eaters, and had adopted vegetarianism as a ploy to defeat Buddhism and to lay claim to its tradition of pacifism and non-violence" (Rao 17). The untouchables were Buddhists or "broken men" who became dependent on dead cattle for survival. While earlier, Brahmins had considered cows sacred on account of their meat, in order to keep the "impure" caste at a distance, Brahmins later made beef taboo; "their sacredness now became an excuse for their protection" (Ilaiah 23).

The material consequences of untouchability over the centuries have been poverty, illiteracy, gender inequality, and caste violence. Tamil Dalit feminist poets, echoing Periyar, believe that action based on logic and reasoning is the only way to overturn casteism. Knowledge was considered the purview of the upper caste (Brahmins), as were physical spaces, such as temples, schools and other public institutions and physical spaces. In a recent poem, "Why Am I a Hindu?" Sukirtharani uses satire to expose the crude customs of Hindus. She sarcastically demands that Hindus follow their caste rules toward Dalits. In her long list of do's and don'ts, she includes Hindu rules of purity and temple access. It is to be noted that Brahminical norms inflected Hinduism as a whole. She commands, with heavy irony,

\section{பண்பாட்டுத் திர्रவிழாக்களின்பகேத \\ ஊர்ச்சாமி சிலகைளக \\ தலித் தரெவுக்கள்}

எப்பாேதம் கொண்ட ச சல்லாதீர்கள் (Sukirtharani, lines 
4-7).

("During festivals, / don't ever bring presiding statues / of gods and goddesses / to Dalit-residential areas." [my translation]).

Sukirtharani is referring to the custom of parading statues of elaborately decorated gods and goddesses in palanquins lifted by priests and devotees, or chariots pulled by elephants, followed by a large procession, during Hindu festivals, down the streets of cities, towns and villages, a practice that has been in vogue for centuries. The processions never entered streets where Dalits lived, as the priests and devotees believed they would be polluted and the gods would be desacralised. Many temples do not allow access to Dalits, and this, too, has been challenged by activists in recent decades.

The nationalist struggle for independence from British rule brought up the social injustice of caste purity, for example, Brahmins keeping Dalits at a physical and social distance. Ambedkar argued that maintaining untouchability deprived Dalits of their subjectivity and well-being - mental and physical health, freedom of occupation, freedom of movement, as well as spiritual freedom, liberating Dalits from the imposition of Hindu religion and precepts. Ambedkar explained that the root of untouchability lay in the Brahminical fear of Buddhism's democratic message which appealed to the masses, in contrast to Brahminical restrictions. He explicated how the "broken men" were constructed as polluting and untouchable, which resulted in them becoming impoverished and having to resort to eating the meat of dead cows (Ilaiah 23).

Meena Kandasamy, a Tamil Dalit poet, who writes in English and whose militant tone marks her poetry, critiques current laws in India restricting the eating of beef. Kandasamy questions, in "How to Make the Bitch give Up Beef," "the possibilities of an Islamic-style Hindu fatwa" planned against beef-eaters like her (This PoemWill ProvokeYou, lines 54-55). Kandasamy also mocks Hindu concepts of karma and dharma in poems such as "Justice Is," where she says "Justice is dharma. / Dharma is a bastard" (Poem Hunter, lines 30-33). Sukirtharani's poem, "Why I am a Hindu?" echoes Kandasamy's anger at pollution rules in a democracy. Using the local nomenclature for Dalits, such as "paraya" and "chakili," Sukirtharani sarcastically lists reasons for restricting access to Dalits in temples:

பறநாயும் சக்கிலியும்

தீண்டத்தகாதவர்கள் .

அவர்களகை் 
கோயிலக்களள் நழயை விடாதீர்கள் (Sukirtharani, lines 13-16). ("Don't allow paraya dogs and chakkilis / their polluting presence / into temple premises" [translation mine]).

The pollution rule that separated the savarnas or upper castes from the Shudras and Dalits was, and still is, built into Brahmin belief system.

Dalit poetry emerged as oral poetry, songs and music, at a time when reading and writing were denied to Dalits. Even audiences for these performances were restricted to untouchables, since upper castes stayed away from their presence. So it was only in the Bhakti movement, which was between the $8^{\text {th }}$ and $18^{\text {th }}$ centuries, "that we got to hear a few untouchable voices" (Kumar 43). Bhakti poets like Chokhamela and Kabir challenged the caste system in the North, while the Siddha poets of the $8^{\text {th }}$ century were radical voices located in the South. The Siddha tradition goes back thousands of years in ancient Tamil civilisation, older than Sanskrit. The Siddha worship of Shiva and Sakti was devoid of caste. They believed in God as an entity combining the feminine and the masculine. Meditative practices learned from a master initiated the Siddha devotee to access the Divine Feminine and thus reach higher consciousness. Siddha is essentially tantric practice. Siddha practices, which consisted of breath practices, yoga, medicine, and alchemy, were conveyed in the form of poetry. ${ }^{8}$ For example, the Siddha poet, Sivavakkiyar admonishes his audience that they will not find God in caste division. "Melt with the Heart Inside / and proclaim the Truth./ Then you will join the Light-/ Life without servitude" (Sivavakkiyar "Padal").

Tamil Dalit feminist poets' genealogy, originating with the radical tradition of non-binary thinking of Siddha poets, continued in the rationalism of Periyar, his establishment of the Dravida Kazhagam or the Dravidian political party $(\mathrm{DMK})^{9}$, and the strong political pride in Dravidian stock laid deep by the hegemony of Tamil literary tradition. True to Dalit political tradition of challenging history, in recent Facebook posts, Sukirtharani and other Dalit activists wrote about the need to destroy the statue of Manu. Manusmriti, ascribed to Manu in the 1500s BCE and translated into English by Sir William Jones in 1776, set some of the law codes followed by Hindus, which were selected and made part of British Colonial law. While there are stanzas in the Manusmriti that describe women's right to property, there are others that contradict it. For example, "Chapter 8, shloka 416 removes all ambiguity by stating: 'Wife, son and slave - all these three, tradition tells us, are without property. Whatever, they may earn becomes the 
property of the man to whom they belong'” (Ali n.p.). Several stanzas place restrictions and punishments for women and Shudras. ${ }^{10}$ For example, "A Brahmin having taken a Shudra woman to his bed goes the lower course; having begotten her a son, he is surely deprived of his Brahminhood" (Ambedkar Who Were the Shudras? 61). Manu's laws did not just forbid intercaste marriage but doled out punishments to men and women who transgressed caste proscriptions. Although the laws of Manu mainly list punishments for Shudras, the lowest caste, the Dalits on account of being outside the four-tier caste system, bore severe punishments for alleged transgressions. The stanzas that have caused much ire are the ones that advocate caste division and subjugation of the Shudras. In fact, Ambedkar burned Manu's book decrying its casteism, while Mahatama Gandhi admonished Ambedkar for doing so, since he believed problems lay with society, not the book of Manu. ${ }^{11}$ Today the debate about Manu has resurfaced: while Hindutva ideologues (people who believe in a Hindu nation) honor him, many progressives deplore him for his demeaning of women and Shudras, since these laws were used by the British to create the Indian Penal Code and of late are influencing law and behavior.

\section{Aesthetics of Tamil Dalit Feminist Poetry}

Rational and materialist philosophies of Periyar nourish Tamil Dalit feminist poetry. We witness a marriage of imagination and logical reasoning, which counters Vedic idealism. Because of the radical ways in which Dalit Tamil feminist poets use syntax, form, image, wit, and metaphor, the subjects they deal with are filled with an energy and insight that we may not see in mainstream poetry. Sukirtharani, Meena Kandasamy, Malathi Maithri and Ku Uma Devi use these poetic devices in their interrogation of injustices meted out to Dalit men and women. The experience, enactment, and witnessing of suffering are the raw materials for their poems. The restrictions they write about range from choice of food, admission to public places, access to justice, sexual taboos, and choice of worship and work. In contemporary India, added to the lack of access to public places are dietary restrictions, such as the rule against beef eating in many states, and the preponderance of daily injustices against Dalits. These become the subjects for Dalit poets, especially the violence against Dalit women, which has become more visible because of more reporting through the spread of technology and social media.

Satire combines both imagination and logical reasoning to achieve aes- 
thetic completion. In Tamil Dalit feminist poetry, we hear the echoes of Periyar's logical reasoning in Why Are Women Enslaved? and other speeches. Consider Sukirtharani's use of satire in her poem, "Why am I a Hindu?" She asserts that she is after all a Hindu who is speaking about how she, a Dalit, is being restricted. She is claiming her Hindu-ness as a Dalit. This brings a new dimension to our understanding of Hinduism: it cannot claim 'purity' and build a wall around it. If Dalits are Hindus, then Hindus cannot afford to restrict Dalits as they, too, are part of Hindu culture. Over the centuries, Dalits converted to Hinduism, Islam, Christianity, Sikhism and Buddhism. Whatever be their religion, Dalit poets critique Brahminism and its dominance in Hinduism. What we see in Dalit feminist texts is the fierce desire of unhooking from the dominant culture and connecting to it on their own terms. We see this decolonisation in Sukirtharani's "Why am I a Hindu?"

Ku Uma Devi, in "Deities," draws on an ontological reality to emphasise the epistemology of caste oppression. In describing the hands, pulling the reins of the chariot bearing the aggressive female deities, she casts her scathing critique of the upper caste which is twisting the reins tight on the Dalits, keeping them in their downtrodden condition:

உக்கிரக் கோலத்தவைட

வடம்பிடிக்கும் ககைள்

மிகக்கொடியதாய்

திரிக்கப்பட்ட கயிரின,ம் வலியதாய்

ஜாதியபை் பற்றியிரகுக்கின்றன (Devi, lines 9-13).

("more than their [the goddess'] rage-filled demeanor, / are the corded hands / twisting the ropes painfully / tightening them around caste" [translation mine]).

Devi invokes Manimekalai, the heroine of Ilango Adigal's eponymous epic, whose representation combines the ideals of the goddess, Buddhism and feminism. In critiquing upper caste oppression, Dalit poets look outside the margins of dominant religion in counter-cultural spiritual practices to find sustenance in literary figures that challenge the system. Devi claims:

அடங்கி / ஒடுங்கி / பக்கவமாய்ப் பயணிக்கின்றோம் / மணிமகேலயைின் / தடம்நாடி (Devi, lines 47-50).

(suppressed, obedient, aware, we pulsate with Manikekalai [translation mine]). 
In presenting a transformation of the oppressed as the actual deities, she hails the heroine Manimekalai from the ancient epic who followed the path of Buddhism. In this assertion, Devi echoes Ambedkar's Dalit subjectivity. Following his defiant espousal of Buddhism, the speaker in this poem follows the path of Manimekalai toward finding liberation outside oppressive boundaries. This choice was part of the long history of Hindus disillusioned by the caste system who turned to Buddhism, since the time of Buddha. Women found liberation in joining Buddhist monasteries and leading the lives of nuns, thus breaking entirely with patriarchy and religious domination.

Devi's poem is marked by anger, irony, and surprise. Her poem ends shifting the burden of oppression on the oppressors and lifting the oppressed to the realm of deities, who are indeed 'untouchable', for they are divine, beyond the realm of human limitations. Tone and voice are crucial in Dalit feminist poetry, since Dalit feminists claim their subjectivity in a structure which negates it. Like her contemporaries, Meena Kandasamy 'too' combines imagination in the aesthetics of form and rationalism to counter Vedic idealism. Kandasamy makes interesting use of juxtaposition to achieve her ironic view of the establishment. Consider her poem, “Advaita:The Ultimate Question,” which is divided into two columns to indicate the division between castes, the Dalits at an untouchable distance from the ruling caste:

One More Final Question

Can My

Untouchable Atman

And Your

Brahmin Atman

Ever Be

One? (Kandasamy, Poem Hunter, lines 16-22).

The above poem unravels the union of matter and spirit that Vedic philosophy espouses. In fact, it is Dalit materiality with its significance placed on the body that gains traction.

\section{Themes of Land, Body, and Sexuality in Dalit Feminist Poetry}

Dalit materiality is about the reality of the suffering Dalit body, the occupation of Dalit land and labor, the violence against the Dalit woman's body, and the denial of sexual autonomy to Dalit women within patriarchy. Tamil Dalit feminist poets bring out their awareness of the precarious materiality of the lives 
of men and women in their community; their poems express the unrelenting violence unleashed on their land, the sweat of their labor and the violence done to them physically and psychologically. However, the poets use poetry to reclaim their voice and their body; they occupy the literary space and in doing so, they occupy psychologically the spaces in society which are denied to them. In tune with the theme of decolonisation, Sukirtharani, in "Why am I a Hindu?" couches her poem within her people's call for the return of Panchami lands, because she wishes to question her location in Tamil and Hindu history. During British rule, the Dalits in Tamil Nadu known as Panchamars, were given land to cultivate, so the British could gain part of the revenue. After Independence, these lands, known as Panchami lands, were forcibly removed from Dalits by landlords and also by government officials; they also flouted the rule not to sell the property to non-Dalits. Recently, Dalits have been calling for the return of their lost lands. The cases are now in court facing challenges of tracing ownership and the legality of transferability. In her poem, "Why Am I a Hindu?" Sukirtharani creates a space for her claiming of ownership of the land which rightly belongs to her ancestors. While the cases grind inexorably slowly in Indian courts, Dalit poets launch an instantaneous revolution.

Daily accumulation of violence on Dalit women and depriving Dalits of their land pervade Dalit poetry. In trying to reclaim their land and their body, Dalit feminists challenge the colonisation of land and woman. Sukirtharani's lament in the refrain, "the untouchable," in her elegy, "My Body is Worth the Touch" ("Theenda thakum en udal") is written on Manisha's, a young Dalit girl, raped and murdered in 2020. Through a list of images and her use of the refrain, "Don't touch," she builds a crescendo toward the final irony. Even the deity (which remains unnamed in the poem) is "untouched," as are the pond, the hut, the very bodies of Dalit women. The poet suggests that if the deity cannot be touched, ultimately the deity is mere stone; there is no justice in a caste-ridden system for women in the lower castes. Interestingly, Ambedkar points out that the root of the word untouchability is "touch" which in its lexicon ironically both connects and separates castes (Ilaiah 162). Touch translates into sight, smell and the very presence of the casteised female body.

Dalit feminist poets deterritorialise colonised spaces, finding body autonomy "within ... psychological, sexual, and spiritual borderlands" (Anzaldua qtd. in Katrak xxvi). Sexuality is a dominant theme in Dalit feminist poetry, since 
Dalit feminist poets assert their space as women, as Dalits, and as sexual beings. Since the sexuality of Dalit women is commodified due to class and caste, often in their poverty-stricken circumstances, we see that Dalit women have "internalized a moral value system that renders them torn between the ethical and the pragmatic" (Sukhirtharani “Tamil Dalit Literature” n.p.), as well as between a body-denying upper caste patriarchal narrative and political movements in literature and society that are agentic. Since the woman is seen as belonging to a father or to a husband, she does not have her own space, physically and psychologically. Her body is seen as not her own but as something that is available for use. Sukirtharani explains with an example of how fraught the Dalit woman's body is. If upper caste men are fighting with each other about something, their attack is restricted to their adversaries. But if upper caste men are fighting with Dalit families, they attack the women in order to punish the whole family (Sukirtharani “Interview"). This lack of ownership of one's own body, one's sexuality, one's movement in public space, is the subject of Sukirtharani's poems in her collection Iravu Mirugam (Animals of the Night). When she is criticised for writing about the vagina, she shoots back:

The female body is never allowed to be in solitude, it is always defined by the man who possesses it, who makes love to it, or by whom it was born to. Love and sex are the same and even if they are not, the two desires emerge from the same body. It is quite normal for a man to flaunt his sexuality, but a woman can never do so: if she does, it is said to be a sin. The society censures female sexuality. (Sukirtharani “Interview")

In Sukirtharani's statement, we can hear Periyar's radical critique of chastity as gendered and oppressive. He states, "we can state several couplets from the Thirukural to show that both the sexes are not given the same rules for chastity" (Periyar 13). Periyar calls out the author of the Thirukural, Thiriuvalluvar, and the commentators of this literary work, arguing that the intention of the verses on female chastity is that "it is not obligatory for men," but only for women (13).

Periyar equates the denial of power to women with the lack of power of Dalits. The body becomes the site of this denial of power. He writes, "[just] because women become pregnant for ten months and give birth to children, it doesn't mean that women's state has to be any different from men when it comes to bravery, anger, leadership, and strength. Or just because men don't become pregnant and give birth to children, their love, calmness and caring will not be different from women" (Periyar 12). Continuing this gender equality theory, Sukirtharani asserts her space in "The Flag of Freedom," by laying claim to 
her body and by making the body as the site of political resistance. She writes, "At the top of the pole / planted in my vagina / the flag of our freedom shall fly / painted in the colour of blood" (Sukirtharani, lines 30-33), referring to Dalit men and women who have died in recent years fighting against caste oppression. Women are expected to be pure, while men are expected to be sexual, and this perception leads to tragic consequences for women; they are punished for any expression of sexuality outside of the norms set by patriarchy and caste.

The materiality of the Dalit woman's body and its relationship to landproperty and physical space within the home and community-needs to be seen in contrast to "the dimension in Hindu mythology that recognizes the spiritual in the physical, often regarding the body as the vehicle to reach spiritual heights... [which] has dangerous consequences for women," often making them mystify sexuality and deny themselves pleasure and suppress desire (Katrak 173). True to Ketu Katrak's statements that protagonists in women's stories achieve "self-awareness ... through the body and not through its denial" (176) and take creative risks to "confront domination" (Katrak 3), Dalit feminist poets boldly and creatively use language to write about sexuality. Malathi Maitri's concerns are with language and poetic craft in depicting female desire, and wresting them out of struggle. In "Demon Language," she writes:

"The demon's features are all woman woman's features are all demon Demon language is poetry" (Maitri, lines 1-6).

Lakshmi Holmstrom, who translates "Demon Language” into English, describes the reference to "demon" thus: "The reference throughout this poem is to Karaikkal Ammai, one of the sixty-three canonised Saiva saints, who lived in the 6th century CE. Punithavathy (the 'sacred' or 'holy'), as she was known in the world, was abandoned by her husband when he realised her extraordinary qualities. She then renounced her youth and beauty, took the form of a demon, and became a poet-saint devoted only to Siva" (Holmstrom 101).

Apart from this allusion to the poet saint, we can look at 'demon' as the speaker reclaiming that which is outside normative structures. The female demon in Hindu tales was described as belonging to the clan that lived and behaved in ways contrary to the rules set by the dominant caste. They were called 'asuras' 
(demons) and were condemned in the ancient tales. The language of feminism that feminist poets are employing are also outside normative structures of signification; they are non-linear, creative, and conceive an imaginary that terrifies the mainstream. Woman herself when uncontained becomes demon or whore. Maitri sees both woman and language as uncontainable, since creativity cannot be stifled. This is echoed by Sukirtharani in "Iyarkaiyin Perurru" ("Nature's Fountainhead"):

"The more you confine me, the more I will spill over

Nature's fountainhead" (Sukirtharani, lines 25-26)

Maitri, as a feminist poet and as a Dalit, knows the texture of being marginal but alive: Demon and woman, according to her, are the same. When woman is given the appellation of demon, it is to be celebrated!

Vasugi Kailasam, in her review of Wild Girls, locates Malathi Maithri's poetry within the categories of Tamil literary spatial markers:

In Tamil cultural consciousness, spatial markers are key points through which personal and group identities are mediated. Thinai is a theorization derived rom the earliest Tamil grammar treatise Tholkappiyam and the term denotes a theoretical register that comprehensively maps out the cultural and social worlds of Tamil regions. ${ }^{12}$ Tholkappiyam has five thinais for the akam classification: Kurunchi (mountains and surrounding areas), Mullai (forests), Marutham (agricultural lands), Paalai (deserts), and Neythal (sea and coastal landscape). Each thinai has a charactertistic flower, a landscape, time, season, music, bird, a beast, tree or plant, water (rivers, ponds), occupation, deities and people.

In her imaginative journeying through her subjective terrain and nature, Maitri demonstrates that the traditional categories do not include her experiences, since these spaces were denied to her. In "Demon Language," Maitri places her language along with woman and demon outside the margins. They transform each other and it is this transformed being that we encounter in Tamil Dalit feminist poetry.

Dalit feminist poets make art out of their lived experiences. Since pollution of presence and touch, menstruation, and other taboos accumulate in the marginalisation of Dalit women, their poetics challenge these taboos. Questions about human emotion and behavior nestle within observations of nature and the minute details of the local. They see woman's body and nature as extensions of each other. In contrast, society sees woman as polluting, while seeing nature as pure. Maitri and Sukirthrani do not differentiate between woman's body, woman's nature and the nature outside. In "My Body," Sukirtharani describes a dynamic landscape and personalises it: "The day's heat / dissolves into the night's 
coolness. / In the end Nature becomes my body, lying still” (Sukirtharani, lines 17-19).

Likewise, Maitri addresses sexuality both in the particular as well as within nature. In "Mental Illness," the character hallucinates terror. Visual and auditory images of brokenness end with the sun itself becoming mired in a bog of meat, and the speaker wonders who will now rescue it. It is as if nature itself succumbs to extinction that is human-made. Together with poems of breakage, Malathi Maitri also writes poems of celebration of the female body. In "Large as the World,"the poet writes: "My vagina as a butterfly, /Flitting about among the hills" (Maitri, lines 25-26). In "Proscribed Blood 1"and "Proscribed Blood 2,"she writes about the half-female goodness who asserts her wholeness during her menstruation (Maitri, Poetry Internatinal). "The Dalit aesthetic cuts across the poetics of language because of the close emotional link between land, labor, and the body, a relationship of both love and anguish" (Holmstrom 27). Metaphorical leaps achieve some of this linking. Consider Maitri's "Alaikal" ("Waves"): The refrain, "ஜன்னலதை் திறந்தால் / கடல் தரெயயும் வீடு" (Maitri, lines 1-2) "The house whose windows / open to the sea" (translation mine), leads to an interesting leap in the last stanza, from observation of the waves and the house next door to the smell of coupling, to the existence of the reader and poet as voyeurs, two fish in an aquarium:

திருப்தியான சம்பாேகம் களாண்ட

உடல்களிலிர్ுந்த பரவும் வாசனை

பக்கத்த வீட்டில் கொதிக்கும்

மீன் கழம்பின் மணம்

யார் வீட்டுத் தொலபைசேயயோ

ஒலித்தக்கொண்டிரகக்கிறத

ஜன்னலதை் திறந்தால்

கடல் தரெியும் வீட்டில்

கண்ணாடித் தனாட்டிக்கள்

நீயும் நான,ம் மீன்கள் (Maitri, lines 31-40).

("From next door, the smell of orgasm / from the satisfied coupling of bodies, / smell of boiling fish soup, / someone's blaring telephone. / / In the house whose windows / open to the sea, you and I are / fish in an aquarium" [translation mine]). 
Similarly in her much appreciated poem, "Tiger," Maitri shows her deft handling of mystery: the wild animal that becomes the intimate warmth of a daughter, and then disappears leaving the "island of sand" next to her sleeping form, suggests the presence of the wild, the mystery that is always there, yet unseen. Maitri shows that she can achieve this deftness of metaphor and suggestion even while using free verse and modern Tamil, thus raising spoken, accessible Tamil into high art.

Maitri's poem, "Veli" ("Day") is her ars poetica. It depicts the struggle of the poet, lines wringing out blood as they betray the poet and drip into emptiness:

இறதிவரியில் என்னக் கொலசையெ

கவிதயைின் விளிம்பிலிர्रந்த குருதி

வறெமயைில் சொட்டட்டும் (Maitri, lines 5-7).

("the betrayal of the poem's final line / blood dripping from its rim into / emptiness" [translation mine]).

Although the experience of being churned out by language is shared by poets, for the Dalit feminist poet, the act of writing is an overwhelming act of the body wrung by language and experience; the poetry of struggle and the poetry capturing that struggle are painful. The poet shows how she can use language to frame it into an agonising beauty. The suffering, of course, never remains within its frame; it exists around and beyond the poem. In Maitri's lines, we see decolonisation as a struggle; it is a painful art which uses material experience of the female body in the world. The hope, if we can dare use that word, is that this pain transmutes unapologetic hegemons of power into allies.

\section{Dalit Feminist Poets' Political Sustenance in Oral Tradition:}

Dalit feminist poets use their literary power to respond to casteism and gender oppression. The poetry discussed in this paper is part of a long history of oral tradition of songs, repeated, memorised, and handed down the generations. Naatu paadal or folk songs have been the heart of festivals celebrating harvest, marriage, death, birth, and other rites of passage. They are political and have also been used to lampoon injustices, offer succor, and accompany physical labor. "Songs remain the sinew of Dalit protest in almost all its configurations" (Ge n.p.). Dalit songs reveal the materiality of their lives, laboring in the fields and at home, loving, birthing, dying, feeding, and celebrating, and include nature and animals as part 
of their landscape. Currently, these songs respond to the traditional strictures against Dalits, from Manu's caste strictures to Gandhi's and Ambedkar's feud over overthrowing the caste system and allowing Dalits temple access. The most recent song that went viral was the PALA song satirising the rule in Sabarimala of denying temple access to women. Woman are seen as a threat in sacral spaces. Temples consider menstruating women as dirty. Dalit women face the dual taboo of being Dalit and women and therefore cannot gain entry to the temple. So the Sabarimala temple remained the one temple continuing to enforce gender inequality, which was upended recently by the Supreme Court. Listing all the behavior codes that men have broken, such as eating food cooked by their wives and daughters, not being chaste, eating mutton, smoking, and drinking alcohol, the singers ask cheekily why they can't break one more taboo by admitting women into the temple. The song ends with: "this is not a tradition, but a curse, a curse that continues to chase God's own country" (PALA). Dr. Ambedkar asks, "Is temple entry to be the final goal of the advancement in the social status of the Depressed Classes in the Hindu fold? Or is it only the first step and if it is the first step, what is the ultimate goal?" ("Sabarimala Dalits" n.p.). Dr. Ambedkar's argument was to denounce Hinduism and adopt Buddhism; since his politics was based on socio-political understanding of society, he realised the structure of the dominant stream of Hinduism would not benefit Dalits. The singers assert their position within Hinduism, blending their faith and their social positioning, thus challenging the structure of religion and society.

Currently, in the spirit of poetry as a vehicle for dissent, Dalit Tamil feminists have developed the tradition of song into spoken word, rap and hip-hop. Isaivani is a popular rap artist, whose songs depict the political greatness of Dalit leaders, the injustices faced by Dalits, and the political and social achievements of Dalits. Male Dalit lyricists have entered the film industry and have contributed there. But it is the pulse of Dalit feminism that we hear in the songs of Isaivani and her group called "The Casteless Collective" (Ilaiah 21). The songs are widely accessible, blending folk and rap to express political themes, and are consumed by both the youth and the older generation across caste.

\section{Decolonising Writing and Feminism:}

Writing in the accessible, spoken Tamil, Tamil Dalit poets radically disrupt the elitist and masculinist construction of literary standards. Across caste and class 
in India, women have less access to education. Women continue to be judged by standards created by men. In literary production, language and creativity also fall into traditional measures of judgement. In Tamil, literary production has been in Cen Tamil or 'literary' Tamil which is quite different from spoken Tamil. So one can only imagine the difficulties Dalit women must have encountered, until recently, in gaining access to publication, which is closely guarded by the literary pundits. In addition, another hurdle Dalit writers face is the genre in which they produce work. Dalit literature is marginalised as "conceptual production" consisting merely of "works of poetry, short stories, and other forms of writing" as opposed to academic writing contributing to "knowledge production in Indian feminism" (Arya 15). This is both a casteist and a masculinist approach to critiquing Dalit writing. Tamil Dalit feminist poetry is a poetry of dissent that employs radical aesthetics. As Meena Kandasamy observes, "[Dalit poetry] tramples all conventions with its intensely personal expression; is concerned with the life of the subaltern, and deals out a stark brutality. This literature should be viewed not as a literature of vengeance or a literature of hatred, but a literature of freedom and greatness" ("Brief Introduction" par. 7).

The sexual politics that is foregrounded in middle-class feminism gives way in Dalit experience to men and women sharing the same experience of caste oppression. So, feminist ideas are not found only in women's writing but in men's writing as well. When we talk of Dalit feminism, we look at the portrayal of feminism beyond gender categories. For example, Tamil Dalit novelists like Imayam and Perumal Murugan depict women's suffering, their activism, and their survival. Sexual harassment, rape of women who work for upper caste landowners or patrons, threats to raped women by upper caste men forcing them to silence, are themes in the novels by Imayam. He writes about the dilemma of sex workers between morality and self-preservation, in his novel Arumugam ("Tamil Dalit Literature").

Dalit feminism is not separatist, but finds meaning in solidarity. It is not surprising to find male Dalit writers exploring feminist themes. The tradition goes back to earlier centuries in Tamil literature. In line with Periyar's outspokenness against all kinds of slavery including the bond of marriage, Tamil Dalit male poets write about violence against women. But we do not see the visceral nature of the violence as we do in the poems written by Dalit women. Of course, the shared witness of injustice is paramount. In "Goddess of Kollangottu," N.D. 
Rajkumar tells of Dalit women victims becoming goddesses screaming for revenge against the Brahmin men who prey on them. In recounting the tragedy of a female victim in his poem, Rajkumar inserts the continuity of the rape in the rapist's belief and desire in his reincarnation to continue his violence: girl from Kollathi

began to wash the dishes

in the back lot, she was forced into intercourse.

After feeding on her

the Brahmin promised to come

in his next life, too.

She killed herself and

now comes

as the goddess of Kollangottu,

screaming for human sacrifice (Rajkumar, lines 5-15).

The poem ends with the victim becoming goddess Isaki demanding "blood-filled rice." In her interview with the poet, Anushiya Sivanarayanan, translator of his poem "Goddess of Kollangottu," says that the Dalit women who die violently are turned into deities. She quotes Rajkumar, "Our gods are jungle gods".

As Uma Chakravarti points out, although Dalit women do not bear the burden of honor, respect and shame that upper caste women carry, "it is not as if patriarchies do not exist among the Dalit castes, or that Dalit women do not have to struggle against the patriarchies within their own communities." She quotes the poet, Swaroopa Rani, "In the home male arrogance / Sets my cheek stinging, / While in the street caste arrogance / Splits the other cheek open" (Chakravarti 61). In the documentary, SheWrite, which is about four Tamil feminist poets, Salma, Kutti Revathi, Sukirtharani and Malathi Maitri, the narratives illustrate the obstacles faced by these poets. Their families try to prevent their daughters or wives from writing and publishing due to the shame they would face in society. Since these poets openly write about sexuality, they get hate mail and they face danger in some public places. Within restricted spaces both in the family and outside in the world they pursue their craft with urgency, often strategising the best way to get their voices heard. We see the ways in which they negotiate with their fathers and husbands, their radical poetry stemming from the contested private and public spaces they inhabit (SMCSchannel).

Violence against women in Dalit families is inseparable from the violence of a patriarchal culture that is steeped in caste oppression. But Dalit feminist 
poets and organisations such as 'The Casteless Collective' try to build awareness of the common struggle of the whole community against hegemonic structures. Poetry brings awareness of the plight of Dalit women within and outside the family. In the postcolony, the Dalit Tamil feminist poets show us that in their situation nothing is 'post' and their caste subjugation exceeds colonial oppression. In fact, under the British, they were granted lands, which were then taken away after Independence, and this land repatriation has come back into question today. Today Dalit women attempt to decolonise the upper caste hegemony, violence done to their bodies and sexual oppression. Dalit feminist poets offer us their process of decolonisation in poetry. The themes Dalit poets deal with spill outside the margins of their poems into a society marked by its diversity. Dalit feminist poetry holds up the mirror to a democracy that is indeed struggling to live up to its democratic ideals of equality and liberty for all people. If the public and private spaces of the Dalit woman are colonised by the majority culture, can collective solidarities help Dalits achieve liberation? Decolonisation is a dance that goes one step forward and two steps back, but is nevertheless negotiated in all spheres - of government, grassroots movements, literary production, literary and cultural criticism, history, ethnography, human rights studies, legal systems, and so on. The voices of Ambedkar and Periyar echo in the poems of Tamil Dalit feminist poets. Periyar's advocacy for Dalit women, his push to decolonise Dalit minds from the strangleholds of Brahminism and colonial political legacy is today felt in the pulse of poetry and song of Tamil Dalit feminists. As Tamil Dalit feminist poets show, radical decolonisation is a deconstruction of existing systems of privilege. These poets enact their radical epistemology through a poetry of wit, irony, humor, subverting assumptions and showing the frailties of society in the looking glass of their poems.

\section{Notes}

1. For further elucidation of Advaita and Vedic idealism, see Sangeeta Menon, “Advaita Vedanta," Internet Encyclopedia of Philosophy, https://iep.utm.edu/ adv-veda/.

2. Ngugi wa Thiong'o, in "Decolonising the Mind," argues for the need to overthrow European imperialism, not just politically, but psychologically and culturally as well. See Ngũgĩ wa Thiong'o. Decolonising the Mind :The Politics of Language in African Literature. Heinemann, 1986. 
3. Since Tamil is in two registers, literary and every day, I use the term "diglossia." Dalit poets defy accepted literary registers and use everyday speech in their poems. Mikhail Bakhtin uses the term "heteroglossia" to describe the values that underline different speech registers.

4. I humbly confess that fully knowing that translation itself is a misreading of the original text, I have attempted to convey in my translations the image, satire, and wit in the original text. However, I use some available English translations in some of the poems. My translation reflects my own journey of teaching myself to read Tamil and translate Tamil poetry. I have also used my skills as a poet in translating the selected quotes.

5. "Dalit" means "broken" in Pali and in Sanskrit. Jotibarao Phule was the first to use the term to describe the oppressed. See Raj Kumar, 4.

6. Mahatma Gandhi used the term "Harijan," or children of God, to describe Dalits. The official term that is used by the Indian government is Depressed Classes. See Guha, 151 .

7. Gayatri Spivak in "Can the Subaltern Speak?" examines the inability of the vulnerable to be heard in capitalist and ideological structures.

8. For more, see https: / / nandhiji.com/who-are-the-siddhas / .

9. Some of the people from Periyar's party, Dravida Kazhagam, formed a new party, the Dravida Munetra Kazhagam (DMK) which has continued to win elections in Tamil Nadu since 1967, defeating the Congress party. See Guha, 224.

10. The Shudras occupied the lowest in the four-tier varna or caste hierarchy, dominated by the castes above them: Brahmin, Kshatriya and Vaishya. The people who were even lower than the Shudras and fell outside the varna system were the untouchables, who were known officially as the Depressed Classes, and later, as the Scheduled Classes, in India.

11. Gandhi interpellated the untouchables, or avarna, the ones who were outside the four major caste divisions, as "Harijan", or "children of God," seeking to end caste discrimination. But he upheld the caste divisions as sanctioned in Hindu religious texts. Ambedkar challenged Gandhi and called for the annihilation of caste, arguing that caste discrimination is undemocratic. Ambedkar took his argument a step further and called for "annihilating the religious notions on which [it] the caste system is founded" (Ambedkar 188), i.e. the sacred tests themselves. 12. Tholkappiyam is an ancient Tamil grammar text written in the $1^{\text {st }}$ or $2^{\text {nd }}$ century BCE. Apart from grammar, it also consists of prosody. One section of the 
Tholkappiyam consists of the genre of love poems, called akam and the genre of war poems called puram; each of these genres covers the inner and the outer worlds, the individual and society. The love poems or akam consisted of 5 genres or poetical landscapes. Poets used these as guides to composition. See Kailasam. 


\section{Works Cited}

Ali, Subashini. "The Laws of Manu and what they would mean for citizens of the Hindu Rashtra." TheWire, November 2020, www.thewire.in/rights/ manusmriti-hindu-rashtra-rss. Accessed 1 Feb. 2021.

Ambedkar, B. R. Annihilation of Caste, Introduced by Arundhati Roy. Verso, 2014. Print.

Ambedkar, B.R. WhoWere the Shudras? Samyak Prakashan, 2018. Print.

Arya, Sunaina and Akash Singh Rathore. "Introduction." Dalit Feminist Theory; A Reader. Routledge, 2020. Print.

Chakravarti, Uma. "Indian Feminism and Dalit Patriarchy." Dalit Feminist Theory; A Reader. Routledge, 2020. p. 61. Print.

Chatterjee, Partha. "The Nationalist Resolution of the Women's Question.” RecastingWomen: Essays in Indian Colonial History, edited by Kumkum Sangari and Sudesh Vaid. Rutgers, 1990. pp. 233-53. Print.

Gajarawala, Toral Jatin. Untouchable Fictions: Literary Realism and the Crisis of Caste. Fordham UP, 2013. Print.

Ge, Krupa. “The Female Dalit voice, in Dalit Verse." First Post. www.firstpost.com/long-reads/politics-of-dalit-identity-revealedthrough-poetry-3483287.html. Accessed July 202021.

Guha, Ramachandra. Makers of Modern India. The Belknap Press of Harvard UP, 2011. Print.

Holmstrom, Lakshmi. Edited and translated. Wild Girls,WickedWords. Sangam House, 2012. Print.

Ilaiah, Kancha. Beef, Brahmins, and Broken Men. Columbia UP, 2020. Kindle edition.

Jesudasan, Denis. "Panchami: Whose Land is it Any Way?" The Hindu, 17 November 2019.

www.thehindu.com/news/national/tamil-nadu/panchami-whoseland-is-it-anyway/article29995102.ece. Accessed 27 June 2021.

Kailasam, Vasugi. "The More You Confine Me, the More IWill Spill Over.” In Plainspeak.

www.tarshi.net/inplainspeak/voices-the-more-you-confine-me-themore-i-will-spill-over/. Accessed February 2021.

Kandasamy, Meena. "Brief Introduction to Dalit Literature.” Muse India. 2006. Web. 1 Feb. 2021.

---. This PoemWill ProvokeYou. Harper Collins, 2015. Kindle edition.

---. “Justice Is" Poem Hunter. Web. 1 Feb. 2021. 
Katrak, Ketu. Politics of the Female Body. Rutgers, 2006. Web. 27 June 2021.

Ku Uma Devi. "Deities.” First Post. Web. Accessed 1 Feb. 2021.

Kumar, Raj. Dalit Literature and Criticism. Orient Blackswan, 2019. Print.

Maitri, Malathi. "Poems." www.keetru.com/literature/poems/ malathi_maitri_7.php. Accessed 1 Feb. 2021.

---. Poetry International. 1 Nov. 2008. www.poetryinternational.org/pi/poet/12942/Malathi-Maithri/ en/tile. Accessed 1 Feb. 2021.

Menon, Sangeetha. "Advaita Vedanta," Internet Encyclopedia of Philosophy. www.iep.utm.edu/adv-veda/. Accessed 19 July 2021.

Periyar. Why WereWomen Enslaved? Ed. K. Veeramani. Kindle edition. n.d. Rajkumar, N.D. "The Goddess of Kollangottu.” The Shared Mirror. Roundtable India . www.roundtableindia.co.in/lit-blogs/?tag=n-d-rajkumar. Accessed Feb. 2021.

Rao, Anupama. "Who is the Dalit? The Emergence of a New Political Subject." Claiming Power from Below: Dalits and the Subaltern Question in India, edited by Manu Bhagavan and Anne Feldhaus. Oxford UP, 2008. pp. 11-27. Print.

“Sabarimala Dalits." Times Now News. October 19, 2018. www.timesnownews.com/india/article/sabarimala-dalits-keraladalit-women-entry-temples-lord-ayyappa-trivandrum-avarnas-ambed kar-gandhi/301179. 1 Feb. 2021.

Sivaiah, Tata. Periyar: Rationalist Bahujan Socialist Revolutionary and the Crusader against Casteism. Countercurrents. Sept. 17, 2016. www.countercurrents.org/2016/09/periyar-rationalist-bahujan-social ist-revolutionary-and-the-crusader-against-casteism/. Accessed 20 July 2021.

“Sivavakiyyar Padal.” The Shared Mirror. Roundtable India. 27 April 2010. www.roundtableindia.co.in/lit-blogs/?tag=sivavakkiyar. Accessed 1 Feb. 2021.

SMCSchannel. "She Write.” YouTube, YouTube, 24 Sept. 2014, www.youtube.com/watch?v $=$ npY8VRbb7Sg.

Spivak, Gayatri. "Can the Subaltern Speak?" In Marxism and the Interpretation of Culture, edited by Cary Nelson and Lawrence Grossberg. University of Illinois Press, 1988, pp. 271-313.

Sukirtharani. "Why am I a Hindu?" Facebook. October 2020.

---. “My Body.” Lyrik Line. Web. 27 June 2021. 
---. “Theenda Thakum Ed Udal.” Facebook post, 2020.

---. Interview by Divya Karthikeyan. Interview: A Dalit Poet's Explorations into Discrimination and the Female Body. 16 July, 2017. Web. 27 June 2021. ---. “Nature's Fountainhead.”Trans. Lakshmi Holmstrom. Lyric Line. Web. 27 June 2021.

“Tamil Dalit Literature.” Roundtable India. 2010. www.roundtableindia.co.in/index.php?option $=$ com_content $\&$ view $=$ article\&id=1911:tamil-dalit-literature-an-overview\&catid= 20\&Itemid=133. Accessed 1 Feb 2021.

PALA-People's Art and Literary Association. "They Say We Pollute the Temple.” YouTube. 24 Oct. 2018, youtube.com/watch?v=OOo7Xin72vU. 